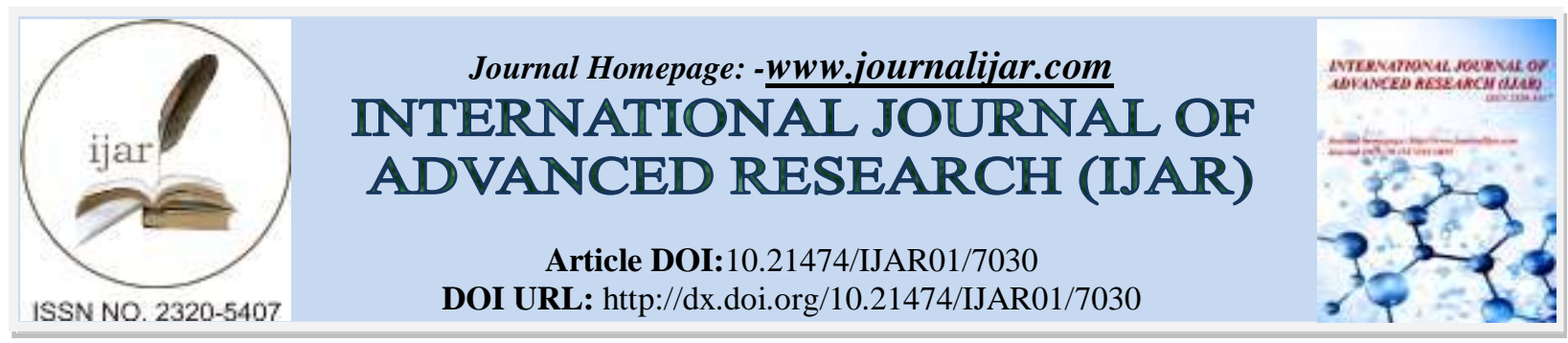

RESEARCH ARTICLE

\title{
LAPAROSCOPY VERSUS LAPAROTOMY IN EVALUATION OF PENETRATING ABDOMINAL INJURIES.
}

\section{Muhammad Ali Baghdadi MD, Amr Ahmed IbrahimMD, Abd-Elrahman Mustafa Metwalli MD, Gamal Muhammad Osman MD and Muhammad Mahmoud Mokhtar MD. \\ General Surgery Department, faculty of medicine, zagazig university, Egypt.}

\section{Manuscript Info}

Manuscript History

Received: 04 March 2018

Final Accepted: 06 April 2018

Published: May 2018

Keywords:-

laparoscopy, laparotomy, penetrating abdominal injuries.

\begin{abstract}
Purpose: to compare the role of laparoscopy versus laparotomy in evaluation of penetrating abdominal injuries in haemodynamically stable patients.

Methods: This study was carried out in the emergency unit of general surgery department in Zagazig university hospitals. The study included sixty patients with penetrating abdominal injuries or equivocal penetration in haemodynamically stable patients. Patients were randomly allocated into two groups, group A underwent laparoscopic exploration of the abdomen and group B underwent exploratory laparotomy.

Results: There was significant difference between both groups regarding hospital stay with short hospital stay for laparoscopic group. In laparotomy group 7 patients had postoperative complications, 2 with post operative ileus, one with pneumonia and 4 with wound infections. In laparoscopic group only one patient had post operative ileus.

Conclusion: Laparoscopy is a helpful diagnostic tool for penetrating abdominal wall injuries to exclude peritoneal penetration. The use of laparoscopy will decrease the rate of negative and non-therapeutic laparotomies, therefore it minimizes the morbidity and decreases the hospital stay.
\end{abstract}

Copy Right, IJAR, 2018,. All rights reserved.

\section{Introduction}

Traumatic injury is the commonest reason behind death in young adults, accounting for a larger loss of productive years of life than heart diseases and cancer together. Blunt injury represents about thirty-nine of all injuries-related death, as transport accidents, falls, and pedestrians smitten by cars. Stab and shooting wounds account for the majority of penetrating trauma deaths and representing about $25 \%$ of all injuries [1].

Laparotomy is the usual surgical treatment of penetrating abdominal injuries. The high percent of non-therapeutic surgical explorations and associated morbidities after mandatory laparotomy for stab wounds abdomen led to the current selective non-operative management plan. The assessment of penetrating abdominal stab wounds for the presence and the severity of intra-abdominal injuries is difficult in spite of presence of different diagnostic tools as, focused abdominal sonography for trauma (FAST), computed tomography (CT), local wound exploration (LWE) , and diagnostic peritoneal lavage (DPL) [2]. 
Laparscopy hase become widely utilized in pelvi-abdominal surgery. Use of laparoscopy in the evaluation and treatment of penetrating abdominal injuries has been increasing [3].

In view of the above, this study was conducted to compare the role of laparoscopy versus laparotomy in evaluation of penetrating abdominal injuries in haemodynamically stable patients.

\section{Materials and Methods}

This study was carried out in the emergency unit of general surgery department in Zagazig university hospitals between May 2015 and April 2017. The study was approved by the Zagazig University Hospital Institutional Review Board. Sixty patients were included in the study, either with penetrating abdominal injuries or equivocal penetration in haemodynamically stable patients.

This is a prospective randomized trial. The Patients were randomly allocated into two groups, group A underwent laparoscopic exploration of the abdomen and group B underwent exploratory laparotomy.

We registered patients neither with gunshot wounds, penetrating injury with blunt abdominal trauma, penetrating injuries in the back or flank, Significant associated extra-abdominal injuries, previous abdominal surgery, signs of diffuse peritonitis nor tension pneumothorax.

All patients were evaluated upon arrival in the emergency department. If patients didn't have an indication for urgent laparotomy (hypotension, intestinal evisceration, diffuse peritonitis, external bleeding, or impalement), they were subjected to Chest X ray, FAST and LWE.

Chest X raywas performed to detect air under diaphragm that indicates peritoneal perforation at least or more intra abdominal injury. FAST was performed to all patients to detect the presence of free fluid. Presence of free fluid was considered as positive finding of peritoneal penetration. LWE was performed in emergency room under local anesthesia for Patients with negative FAST. Patients with intact fascia were discharged from emergency department after closure of the skin and were instructed for follow up in outpatient clinic.

Patients with peritoneal penetration or equivocal penetration were randomly subjected to either laparoscopy or laparotomy. Routine laboratory investigations were done for all patients. Informed consent was obtained from every patient.

Preoperative intravenous antibiotic ceftriaxone $1 \mathrm{gm}$ was administrated to every patient on admission and on induction of anesthesia.

\section{Operative technique:-}

In group A, patients were subjected to Laparoscopic evaluations in the operating room under general anesthesia.

The site of the stab was sutured, then pneumoperitoneum with carbon dioxide was established via veress needle or open technique at the umbilicus. but in 2 cases, the stab was at the umbilicus and we introduced the canula directly through site of the stab.

A forward-viewing laparoscope $\left(30^{\circ}\right)$ was inserted at umbilicus. we inspected the peritoneum at the site of the stab, if it was intact and no intraperitoneal abnormal fluid then the wound was sutured without any further exploration of the abdomen and patient were discharged after recovery from anesthesia.

If there was peritoneal penetration wre detected or abnormal free fluid, two additional 5 and $10 \mathrm{~mm}$ trocars were inserted laterally to the right and left rectus muscles in cases of stab in upper abdomen but positions of additional ports were different according to site of stab.

The site of the surgeon at the patient's left side and the patient was placed in the Trendelenburg position.

We started thorough inspection with the pelvic structures (the sigmoid colon, both groins, both iliac regions, and the bladder). Then we continued inspection of the right side of the colon. The small bowel was inspected from the ileocecal valve to the ligament of Treitz, with thorough inspection of both sides of the mesentery. 
For completeing evaluation of the small bowel and colon, we introduced a non-traumatic grasping forceps through each lateral trocar, and the grasper in the right side was used to grasp the most distal portion of the small bowel, elevate it, and pull it to the right. Next, 4 to 8 in. of the bowel were inspected. The most proximal portion then was grasped with the left-side forceps and "handed off" to the right-side forceps. In this fashion, the same maneuver was repeated many times.

The site of the surgeon was changed to the patient's right side for inspecting the transverse colon, splenic flexure, and descending colon. We placed the patient in the reverse Trendelenburg position for inspecting the liver, stomach, spleen, and diaphragm

During active bleeding, we achieved hemostasis by using diathermy, clips, endoloop-type ligation and sutureligation.

We repaired stomach injuries with intracorporeal sutures.

Drains were inserted in all cases after laparoscopic evaluation and removed after 24 hours if no abnormal discharge came through it.

Conversion to laparotomy was decided if complete abdominal examination can't be performed adequatly or injury can't be repaired by laparoscopy

In group B, patients were subjected to exploratory laparotomy through midline incision with systematic exploration of solid organ, intestine and diaphragm and repair of injuries accordingly.

Patients in whom no injuries detected were followed up in the ward for 24 hours and discharged according to their clinical recovery. Assurance of hemostasis and absence of missed injuries in patients were confirmed by normal postoperative recovery.

All patients were followed up for 2 weeks in outpatient clinic by thorough clinical examination and abdominal ultrasound to detect any complications or missed injuries.

Intra-operative findings were described using standard terminology. Laparotomy was considered negative if there was no peritoneal penetration discovered after the abdomen was opened. Laparotomy was considered nontherapeutic if there was peritoneal penetration with either no visceral and solid organs or very minor injuries that they did not require surgical repair. A therapeutic laparotomy was one that required surgical repair of internal injuries. The laparoscopic findings were considered positive if there was peritoneal penetration and negative if there was no. Patients with positive findings at laparoscopic evaluation may had no intra-abdominal injuries or very minor injuries that need no intervention and then considered non-therapeutic laparoscopy. If injuries of the patients were treated by laparoscopy, it is then considered therapeutic laparoscopy.

Postoperative assessment included operative time, length of hospital stay and complications.

\section{Results:-}

Most of cases were males with the mean age of 27.7 years. Of 60 patients with penetrating abdominal trauma who underwent FAST, 26 had negative FAST findings, of which 17 had no intra abdominal injuries. And 1 had injuries that didn't need intervention and 8 had injuries needed repair (diaphragm, stomach and small intestinal injuries) with sensitivity of $65.4 \%$. 34 patients had positive FAST findings, of which 12 had injuries that didn't need intervention with specificity $100 \%$ Table (1).

Peritoneal penetration detected in patients as follow, 34 with positive FAST, 14 with positive LWE, 5 with omental evisceration, 7 with equivocal penetration.

In laparoscopic group, 3 patients had no peritoneal penetration, 6 patients had peritoneal penetration with no intra abdominal injuries, and 7 patients had intra-abdominal injuries that need no treatment (5 liver tears \& 2 mesenteric tears). 14 patients had injuries that required treatment, we were able to deal with the injuries by laproscopy in 7 patients (diaphragm, stomach and spleen), but 7 patients were converted to laparotomy. 
In laparotomy group, 3 patients had no peritoneal penetration, 5 patients had peritoneal penetration with no intra abdominal injuries, 6 patients had intra-abdominal injuries that need no treatment (4 liver tears \& 2 mesentric tears), and 16 patients had injuries that needed treatment (diaphragm, stomach, spleen and intestine). So non-therapeutic laparotomy rate was $46.6 \%$ in laparotomy group Table (2).

About one third of cases had no intra-abdominal injuries \& $20 \%$ had liver injuries that mostly stopped bleeding at the time of operation Table (3).

Conversion to laparotomy occurred in 7 cases, 3 with splenic injury that need splenectomy ( 2 of which had stomach $\&$ splenic injuries), one with retro-perionealheamatoma due to unsatisfactory laparoscopic exploration, one case had sigmoid and intraperitoneal bladder injury and 2 cases with small intestinal injuries. So non-therapeutic laparotomy rate in laparoscopic group was $14.3 \%$ Table (4).

There were two cases with missed injuries both were detected by the presence of intestinal content in abdominal drains in the next day and were managed by exploration in the same hospital stay, it was small tear in small intestine with no abnormal intraperitoneal fluid at the time of laparoscopic examination.

There was significant difference between both groups regarding hospital stay with less hospital stay for laparoscopic group ( $p=0.004)$ Table (5). But There was significant difference between both groups regarding operative time with less operative time for laparotomy group $(\mathrm{p}<0.001)$ Table $(6)$.

Postoperative complication was noticed only in one patient in laparoscopy group and in seven patients in laparotomy group. In laparotomy group, 2 patients with post operative ileus, one with pneumonia and other 4 with wound infections. In laparoscopic group only one patient developed post operative ileus.

\section{Discussion:-}

Most cases with penetrating abdominal injuries present with no an indication for urgent laparotomy and the nontherapeutic result of routine laparotomy is frequent. Tere are some options in assessing penetrating abdominal injuries include serial clinical assessment, imaging studies, and less invasive procedures (local wound exploration, diagnostic peritoneal lavage, and laparoscopy), but each has disadvantages. Potentially life-threatening injuries could be missed by clinical assessment and imaging studies. Local wound exploration may not helpful in case of the abdominal fascia is violated and wound extension may be required [4].

The main objective of FAST is to detect the presence of intra-peritoneal free fluid which is a sign of acute bleeding, visceral or solid organ injuries [5].

In our study the sensitivity of FAST in detecting intra-abdominal injuries was $65 \%$ and the specificity was $100 \%$, this is in agreement with Biswadev et al. [6], who found the sensitivity and the specificity of FAST were $47.6 \%$ and $95.6 \%$ respectively.

However FAST had a limited role in the diagnosis of penetrating abdominal injuries as stated by Korner et al. [7], in his study about 26-34\% of patients with penetrating abdominal injuries had organ lesions with no intraperitoneal free fluid and about $25 \%$ of these patients required laparotomy.

FAST is a useful diagnostic tool in patients with PAI, but it has low sensitivity, so the decision of surgical exploration can't be taken depending on the results of FAST. In a prospective study by Udobi et al. [8], 54patients had a negative FAST out of 75 with PAI. 13 patients had a false negative FAST out of the 54, and further evaluation demonstrated they had significant organ injuries. So the sensitivity rate in this study was $46 \%$.

Zantut et al. [9] found that sensitivity of FAST is $68-98 \%$ in detecting the presence intra-peritoneal free fluid. The high sensitivity of FAST in this study may be because of the high experience level of US operators and because the results were compared to computed tomography.

The diagnostic values observed for LWE in our study were in agreement with other researches. In our study 21 patients performed LWE of which $6(25 \%)$ went to have no peritoneal penetration, this consistent with Biswadev et al. [6] had 2 (28\%) negative laparotomy after LWE out of 7 patients. 
Taner et al. [10] found LWE sensitivity of $18 \%$ in detecting visceral injuries as his study was to detect sensitivity of LWE for visceral injuries not to detect peritoneal penetration only.

Kawahara et al. [11] found that LWE decrease non therapeutic laparotomy rate from $60 \%$ to less than $50 \%$.

In our study, the rate of peritoneal penetration after stab injuries was $90 \%$ as we found 6 cases $(10 \%)$ of intact peritoneum, in consistent with us Cherry et al. [12] had 6.8\% negative laparotomy and Ahmad et al. [13] found that peritoneal penetration occurred in $91 \%$ of patients undergoing exploratory laparotomy for stab abdomen.

In contrary to us was Jonathan et al. [16] stated that in stab injuries about $70 \%$ of cases had abdominal cavity penetration. Some injuries in these cases with peritoneal penetration are not serious and an unnecessary laparotomy is about 20-30\%. Maciej Wiewióra et al. [15] also found that in 33\% there were no peritoneal penetration \& $29 \%$ had no significant injuries

This is difference because we didn't include cases with intact fascia at LWE in our study. Differences in injury patterns, patient selection, and thresholds for treating injuries at laparotomy may explain some of this variation.

We found the rate of intra-abdominal injuries after stab abdomen was $72 \%$ as we found in $28 \%$ that no intaabdominal injuries detected. This is consistent with Navsariaet al. [16] (75\%) and Ahmad et al. [15] (68\%).

The results of our study demonstrated that the laparoscopy reduced the non-therapeutic laparotomy rate from 46.6 to $14 \%$ and avoided laparotomies in $53 \%$ of PAI cases.

In consitent with us Ivaturyet al. [17] found that $63 \%$ of patients who had laparoscopic evaluation in PAI avoided laparotomy and also Fabian et al. [18] found that laparoscopy reduced non therapeutic laparotomy in PAI from $65 \%$ to $11 \%$, and Gordie et al.[19] stated that laparotomy after diagnostic laparoscopy (DL) reduced unnecessary laparotomies in 55-87\% of PAI cases, also Heng Fu Lin et al. [2] reported zero rate of non therapeutic DL as he used laparoscopy as diagnostic and therapeutic tool and so we did in contrary to us MohsinRaza et al. [4] reported $45 \%$ non therapeutic laparotmy rate after DL.

In our study, Diaphragmatic injuries rate were $6.6 \%$ in contrary to previous study of Murray et al. [20] and, Soccorsa Sofia [21] who found $20 \%$ diaphragmatic injury as, these study were conducted on patients with stab in thoraco-abdominal region only.

Our study found that laparoscope diagnosed all cases of diaphragmatic injury with no missed cases, in consistent with us Kremer [22] and Villavicencio et al. [23] stated that laparoscopy had high sensitivity reaching 100\% in detecting diaphragmatic laceration in thoraco-abdominal penetrating injuries.

We had 7 (23.3\%) cases converted to laparotomy as injuries couldn't be repaired with laparoscopy, this consistent with Benjamin et al. [24] had conversion rate of 9 (25\%) cases out of 36.

In our study, the non-therapeutic laparotomy rate in laparoscopy group is dcreased. In laparoscopy group, 16 out of 30 patients had non-therapeutic laparoscopies. Non-therapeutic laparoscopy is less invasive procedure than nontherapeutic laparotomy.

Emily et al. [25], Fabian et al. [19], and Heng et al. [2] reported fewer complications rate, shorter length of hospital stay, lesser operative time with negative laparoscopy than with negative or non-therapeutic laparotomy.

The results in the present study are similar to the most results of the other studies; show that non-therapeutic laparoscopy is less invasive than non-therapeutic laparotomy.

In our study there is a decrease in hospital stay from 3.1 to 1.9 days ( $\mathrm{p}=0.004)$ In favor of laparoscopy, this is consistent with most of studies comparing laparotomy to laparoscopy as Heng et al. [2] (4.6 to 1.1 days) .

The results of our study (23.3\% of complications in laparotomy group and 3.3\% in laparoscopy group) were consistent with those of other centers regarding the generally accepted laparoscopic advantages of decreased rates of negative laparotomy, shortened the length of hospital stay, and quicker return to normal activity. We found 
overall that the laparotomy patients had higher morbidity. The laparotomy patients had many more pulmonary complications including pneumonia and more wound complications including dehiscence, infection, and abscess formation.

\section{Conclusion:-}

Minimally invasive surgical techniques are particularly helpful as a screening tool for anterior abdominal stab wounds and lower chest injuries to rule out peritoneal penetration. Increased use of laparoscopy in patients with penetrating abdominal injuries will decrease the rate of negative and non-therapeutic laparotomies, thus lowering morbidity and decreasing length of hospital stay.

\section{Conflict of interest}

There are no conflicts of interest.

Table (1): Results of preoperative FAST findings and comparing it with intra-operative findings

\begin{tabular}{|l|l|l|l|l|l|l|}
\hline \multirow{2}{*}{} & \multicolumn{2}{|l|}{$\begin{array}{l}\text { +ve FAST } \\
\text { No.=34 }\end{array}$} & \multicolumn{2}{|l|}{-ve FAST No.=26 } & \multirow{2}{*}{ p. value } \\
\cline { 2 - 6 } & No. & $\%$ & No. & $\%$ & & \\
\cline { 2 - 6 } Negative & 0 & 0.0 & 17 & 65.4 & 32.35 & $<0.001^{* *}$ \\
\hline None therapeutic & 12 & 35.3 & 1 & 3.8 & & \\
\hline Therapeutic & 22 & 64.7 & 8 & 30.8 & & \\
\hline
\end{tabular}

Sensitivity and specificity of FAST are $65.4 \%$ and $100 \%$ respectively.

Table (2): Comparison between laparotomy and Laparoscopy regarding results of abdominal injuries

\begin{tabular}{|l|l|l|l|l|l|l|}
\hline \multirow{2}{*}{} & \multicolumn{2}{|l|}{$\begin{array}{l}\text { Laparotomy group } \\
\text { No.=30 }\end{array}$} & \multicolumn{2}{|l|}{$\begin{array}{l}\text { Laparoscopy group } \\
\text { No.=30 }\end{array}$} & \multirow{2}{*}{ p. value } \\
\cline { 2 - 5 } & No. & $\%$ & No. & $\%$ & & \multirow{2}{*}{0.3} \\
\hline Negative & 3 & 10.0 & 3 & 10.0 & \multirow{2}{*}{0.861} \\
\hline None therapeutic & 11 & 36.7 & 13 & 43.3 & & \\
\hline Therapeutic & 16 & 53.3 & 14 & 46.7 & & \\
\hline
\end{tabular}

Non-therapeutic laparotomy rate was $46.6 \%$ in laparotomy group.

Table (3): Type of intrabdominal injuries

\begin{tabular}{|l|l|l|l|l|l|l|l|l|}
\hline & \multicolumn{2}{|l|}{$\begin{array}{l}\text { Laparotomy } \\
(\mathrm{n}=30)\end{array}$} & \multicolumn{2}{l|}{ A. laparoscopy(n=30) } & \multicolumn{2}{l}{ B. Total } & \multirow{2}{*}{ C. X2 } & \multirow{2}{*}{ D. P } \\
\cline { 2 - 8 } & No. & $\%$ & No. & $\%$ & E. No. & F. \% & & \\
\hline - ve & 8 & 26.7 & 9 & 30.0 & 17 & 28.3 & 0.12 & 0.732 \\
\hline Liver & 6 & 20.0 & 6 & 20.0 & 12 & 20 & 0.17 & 0.683 \\
\hline Stomach & 5 & 16.7 & 4 & 13.3 & 9 & 15 & 0.22 & 0.637 \\
\hline Spleen & 3 & 10.0 & 4 & 13.3 & 7 & 11.6 & 0.29 & 0.593 \\
\hline Mesenteric & 4 & 13.3 & 3 & 10.0 & 7 & 11.6 & 0.29 & 0.593 \\
\hline intestine & 2 & 6.7 & 2 & 6.7 & 4 & 6.6 & 0.5 & 0.479 \\
\hline Diaphragm & 2 & 6.7 & 2 & 6.7 & 4 & 6.6 & 0.5 & 0.479 \\
\hline
\end{tabular}

Table (4): Results of Laparotomies after Conversion

\begin{tabular}{|c|c|c|c|c|c|c|c|c|}
\hline & \multicolumn{2}{|c|}{ Negative } & \multicolumn{2}{|c|}{ None therapeutic } & \multicolumn{2}{|c|}{ Therapeutic } & \multirow[t]{2}{*}{$\chi^{2}$} & \multirow[b]{2}{*}{ p. value } \\
\hline & No. & $\%$ & No. & $\%$ & No. & $\%$ & & \\
\hline $\begin{array}{ll}\text { Conversion to } \\
\text { EL (No.=7) }\end{array}$ & $\mathbf{0}$ & 0.0 & 1 & 14.3 & 6 & 85.7 & 13.29 & $0.001^{*}$ \\
\hline
\end{tabular}

Non-therapeutic laparotomy rate in laparoscopic group was $14.3 \%$. 
Table (5): Comparison between laparotomy and Laparoscopy regarding length of hospital stay

\begin{tabular}{|l|l|l|l|l|l|l|}
\hline \multirow{2}{*}{} & \multicolumn{2}{|l|}{$\begin{array}{l}\text { Laparotomy group } \\
\text { No.=30 }\end{array}$} & \multicolumn{2}{l|}{$\begin{array}{l}\text { Laparoscopy group } \\
\text { No.=30 }\end{array}$} & \multirow{2}{*}{ p. value } \\
\cline { 1 - 6 } & $\overline{\mathrm{X}_{ \pm S D}}$ & Range & $\overline{\mathrm{X}}_{ \pm \text {SD }}$ & Range & & \\
\hline Hospital stays (days) & $3.1 \pm 1$ & $1-8$ & $1.9 \pm 1$ & $0.5-5$ & 3.027 & $0.004^{*}$ \\
\hline
\end{tabular}

There was significant difference between both groups regarding hospital stay with less hospital stay for laparoscopy group.

Table (6): Comparison between laparotomy and Laparoscopy regarding operative time

\begin{tabular}{|l|l|l|l|l|l|l|}
\hline \multirow{2}{*}{} & \multicolumn{2}{|l|}{$\begin{array}{l}\text { Laparotomy group } \\
\text { No.=30 }\end{array}$} & \multicolumn{2}{l|}{$\begin{array}{l}\text { Laparoscopy group } \\
\text { No.=30 }\end{array}$} & \multirow{2}{*}{ p. value } \\
\cline { 2 - 6 } & $\overline{\mathrm{X}_{ \pm S D}}$ & Range & $\overline{\mathrm{X}}_{ \pm \text {SD }}$ & Range & & \\
\hline Operative time (minutes) & 74.519 .9 & $50-120$ & 109.335 .4 & $30-180$ & 4.694 & $<0.001^{* *}$ \\
\hline
\end{tabular}

There was significant difference between both groups regarding operative time with longer operative time for laparoscopy group.

\section{Referrences:-}

1. Robert C, Mackarsie. “Abdominal trauma, essential practice of surgery”. Jeffrey A, Norton, Alfred E, Chang, Stephen F, Lowry. $2^{\text {nd }}$ edition. New York: Springer section two (2003): 355-375.

2. Heng Fu Lin, Jiann Ming Wu, Chao Ching Tu. "Value of diagnostic and therapeutic laparoscopy for abdominal stab wound". World J surg 34 (2010):1653-1662.

3. Leppaniemi A, Haapiainen R. "Diagnostic laparoscopy in abdominal stab wounds; a prospective randomized study”. J trauma 55 (2003): 636-645.

4. MohsinRaza, Yasser Abbas, Vanitha Devi, et al. "Non operative management of abdominal trauma - a 10 years review". World J EmergSurg 5 (2013): 8-14.

5. Kirkpatrick AW, Sirois M, Laupland KB et al. "Prospective evaluation of hand-held focused abdominal sonography for trauma (FAST) in blunt abdominal trauma”. Can J Surg 48 (2005): 453-460.

6. BiswadevMitra, Robert Gocentas, Gerard O'Reilly et al. "Management of haemodynamically stable patients with abdominal stab wounds". Emergency Medicine Australasia 19 (2007): 269-275.

7. Korner M, Krotz MM, Degenhart C, et al. "Current role of emergency US in patients with major trauma". Radiographics 28 (2008): 225-244.

8. Udobi KF, Rodriguez A, Chiu WC, Scalea TM. "Role of ultrasonography in penetrating abdominal trauma: a prospective clinical study". J Trauma 50 (2001): 475-479.

9. Zantut LF, Ivatury RR, Smith RS, Kawahara NT, et al. "Diagnostic and therapeutic laparoscopy for penetrating abdominal trauma: a multicenter experience”. J Trauma 42 (2001): 825-829.

10. Taner AS, Topgul K, Kucukel F et al. "Diagnostic laparoscopy decreases the rate of unnecessary laparotomies and reduces hospital costs in trauma patients". J LaparoendoscAdvSurg Tech 11 (2001): 207-211.

11. Kawahara NT, Alster C, Fujimura I, et al. "Standard examination system for laparoscopy in penetrating abdominal trauma". J Trauma 67 (2009): 589-595.

12. Cherry RA, Eachempti SR, Hydo LJ, Barie PS. "The role of laparoscopy in penetrating abdominal stab wounds". SurgLaparoscEndoscPercutan Tech 15 (2005):14-17.

13. Ahmad N, Whelan J, Brownlee J, et al. "The contribution of laparoscopy in evaluation of penetrating abdominal wounds". J Am CollSurg 201 (2005): 213-216.

14. Jonathan AJ Hyde, and Timothy Grahama. "Conservative management of penetrating torso trauma". Trauma 2 (2000): 187-197.

15. MaciejWiewióra, KrystynSosada, et al. "The role of laparoscopy in abdominal trauma".review of the literature Videosurgery and other mini invasive techniques 5 (2011): 121-126.

16. Navsaria PH, Berli JU, Edu S and Nicol AJ. Non-operative management of abdominal stab wounds--an analysis of 186 patients". S Afr J Surg 45 (2007): 128-130.

17. Ivatury RR, Simon RJ and Stahl WM. "A critical evaluation of laparoscopy in penetrating abdominal trauma". J Trauma 34 (1993): 822-828.

18. Fabian TC, Croce MA, Stewart RM et al. "A prospective analysis of diagnostic laparoscopy in trauma". Ann Surg 65 (1993): 557-565. 
19. Gordie K. Kaban, Yuri W. Novitsky, Liam Haveran, et al. "Use of Laparoscopy in Evaluation and Treatment of Penetrating and Blunt Abdominal Injuries".Surginnov 15 (2008): 26-31.

20. Murray JA, Demetriades D, Asensio JA, Cornwell EE, et al. "Occult injuries to the diaphragm: prospective evaluation of laparoscopy in penetrating injuries to the left lower chest". J Am CollSurg 187 (1998): 626-630.

21. Soccorsa Sofia. "Bedside US imaging in multiple trauma patients". J Ultrasound 16 (2013):147-159.

22. Kremer K. "Diagnostic laparoscopy for trauma". In: Minimally abdominal surgery. Kremer K, Platzer W, Schreiber HW, Steichen FM (eds.). Thieme Stuttgart, New York (2001): 61-68.

23. Villavicencio RTandAucar JA. "Analysis of laparoscopy in trauma”. J Am CollSurg 189 (1999): 11-20.

24. Benjamin S. Powell, Martin A. Croce et al. "Diagnostic laparoscopy for the evaluation of occult diaphragmatic injury following penetrating thoracoabdominal trauma". Injury, Int. J. Care Injured 39 (2008): 530-534.

25. Emily Wilson, David Metcalfe, KapilSugand, et al. "Delayed recognition of diaphragmatic injury caused by penetrating thoraco-abdominal trauma".Int J Surg Case Rep 3 (2012): 544-547. 